\title{
A Case Study of Chinese Students' and IEP Faculty Perceptions of a Creativity and Critical Thinking Course
}

\author{
James Badger ${ }^{1}$ \\ ${ }^{1}$ College of Education, University of North Georgia, Dahlonega, Georgia 30597, USA \\ Correspondence: College of Education, University of North Georgia, Dahlonega, Georgia 30597, USA. Tel: \\ 706-864-1996. E-mail: james.badger@ung.edu
}

Received: March 29, 2019

Accepted: April 16, 2019 Online Published: June 18, 2019

doi:10.5539/hes.v9n3p34

URL: https://doi.org/10.5539/hes.v9n3p34

\begin{abstract}
The attention to fostering learners' critical thinking and creativity skills in secondary school and college students is growing in Western and non-Western countries. This study investigated the integration of a creativity and critical thinking course in an Intensive English Programs (IEP) to determine how the same course may contribute to international students' linguistic skills and analytic abilities in preparation for college. Perry's (1970) conceptual framework was adopted to analyze Chinese students' views of problems presented in a creativity and critical thinking course, and how the same knowledge related to the Chinese students' prior educational experiences as well as connect to their future studies. IEP faculty and administrator's perceptions provided an additional perspective into the purpose and learning outcomes of the same course. Findings from this research address a gap in the literature that seeks effective strategies and models for IEPs to foster international students' analytic skills in preparation for college studies.
\end{abstract}

Keywords: creativity, critical thinking, IEP faculty, Chinese students, college preparation

\section{Introduction}

The attention to fostering learners' creativity and critical thinking skills in secondary school and college students is growing in Western and non-Western countries (Lucas, 2016; Harris \& de Bruin, 2018; Welter, Jaarsveld, \& Lachmann, 2017). In the U.S., there are Centers for Studies in Creativity as well as undergraduate courses and graduate programs devoted to developing students' higher order thinking skills (Pappano, 2014). The call to teach and assess students' critical thinking in U.S. public schools began in 1983 with the federal report, A Nation at Risk (Cross, 2014; Sanavi \& Tarighat, 2014). Contained in the American Association of Colleges and Universities' (AACU, 2008) Liberal Education and America's Promise (LEAP) are essential learning outcomes and sixteen VALUE rubrics associated with each of the LEAP's essential learning outcome. Critical and creative thinking are identified as two of the sixteen LEAP essential learning outcomes to guide student's progress through college and prepare for twenty-first century work, citizenship, and life.

This study investigated the integration of a creativity and critical thinking (C\&CT) course in an Intensive English Program (IEP) to determine how the same course may contribute to international students' linguistic skills and analytic abilities in preparation for college. Many IEPs are located in major American public colleges that serve as an avenue for recruiting international students and prepare international students with English for academic purposes for future studies in American colleges (Steadman \& Kraut, 2018). Perry's (1970) conceptual framework of college students' cognitive growth was adopted to analyze Chinese students' views of the IEP C\&CT course, and how the Chinese students' same perceptions of creativity and critical thinking related to their prior educational experiences and future college studies. The conceptual framework was also used to examine interviewed IEP instructor's and administrator's perception of the same C\&CT course. Two research questions guided the inquiry of this study: What are the learning outcomes of an IEP creativity and critical thinking course? What are Chinese students' and IEP faculty perceptions of a creativity and critical thinking course according to Perry's scheme? The organization of this paper begins with a review of creativity and critical thinking skills in colleges before introducing a brief description of Chinese education. A description of Perry's nine positions of academic and ethical knowledge precedes an explanation of the C\&CT course and analysis of collected qualitative data. Findings from this research address a gap in the literature that seeks effective strategies and models for IEPs to foster international students' analytic skills in preparation for academic studies in 
post-secondary institutions.

\subsection{Creativity and Critical Thinking}

There is an increasing awareness and importance of fostering students' creativity in higher education, regardless of the discipline of study (Marquis \& Henderson, 2015; Jahnke, Haertel, \& Wildt, 2017). Colleges in the U.S. place a high value on creativity and innovation as a critical twenty-first century skill (Shapiro, Farrel, \& Tomas, 2014). According to the AACU (2008), creativity is the "capacity to combine or synthesize existing ideas, images, or expertise in original ways and the experience of thinking, reacting, and working in an imaginative way characterized by a high degree of innovation, divergent thinking, and risk taking... (T)he creative thinker, at the highest levels of performance, pushes beyond the knowledge of a domain's parameters in new, unique, or atypical recombinations, uncovering or critically perceiving new syntheses and using or recognizing creative risk-taking to achieve a solution" (para 3).

Creativity is often described as the result of transforming something new from something that did not exist before in a context that supports student autonomy, freedom, and playfully learning (Cross, 2012). In addition, creativity is supported in an environment that encourages risk-taking, independence, and flexibility (Gibson, 2010). Creativity is not restricted to the arts but is expressed in academic and social situations through collaboration, sense-making, and meaning-making. These and others definitions and conceptualizations position creativity as an important learning outcome in higher education identified by the AACU and others (Jahnke, Haertel, \& Wildt, 2017).

As with creativity, those in higher education view critical thinking as an educational outcome that moves students' epistemologies from surface, unreflective thinking to a position of independence where one can use those same skills and dispositions to understand, evaluate, and problem solve in their academic and social lives (Ghanizadeh, 2017; Moore, 2013). Some authors note that creative thinking and critical thinking share some skills and abilities (Paul, 1993). Critical thinking has been listed as a top priority for undergraduate teaching and learning, yet disagreement over the definition and components of critical thinking remain as well as debate over whether colleges are effectively developing those skills in students (Grant \& Smith, 2018).

Principles of critical thinking often include elements of creativity, curiosity, and deliberation (Lennon, 2014). A critical thinker often questions assumptions, identifies false inferences and logical fallacies, and discerns bias and opinions from facts and evidence (Tan, 2017). Critical thinking skills are cognitive skills that include identifying, analyzing, synthesizing, problem solving and evaluating information to make informed decisions (Shim \& Walczak. 2012), while critical thinking disposition relates to the affective domain of inquisitiveness, truth-seeking, engagement, open-mindedness, self-confidence, and maturity (Pei, Zheng, Zhang, \& Liu, 2017). It is posited that the interplay between critical thinking and reflective thinking contributes to academic achievement and allows one to become more critical of one's own practices to make meaningful change (Ghanizadeh, 2017).

Possessing the skills of critical thinking allows an individual to adopt a position of flexibility, employ the skills of reasoning, and engage in dialogue with oneself (Wang \& Zheng, 2016). Further, thinking critically entails the ability to evaluate the accuracy of information and the comprehensive exploration of issues, ideas, artifacts, and events before accepting a conclusion or formulating an opinion or conclusion (AACU, 2016; Tan 2017). Studies have explored the way beliefs about knowledge and knowing are multidimensional and multilayered, with students' beliefs and perceptions about knowledge and knowing impacting their engagement and understanding of inquiry as well as their academic performance (Buehl \& Alexander, 2001; Getahun, Saroyan, \& Aulls, 2016). The cluster of critical thinking dispositions also includes doubting simplistic answers or solutions and moving from "how" questions to "what" and "why" questions. These and other dispositions are characterized as "habits of mind' that include a willingness to entertain ideas without necessarily accepting them (Wang \& Zheng, 2016).

Instructional approaches that advance the skills of creativity and critical thinking in students are the Socratic Method, Bloom's taxonomy, Fink's taxonomy, and Lonergan's general empirical method (Lennon, 2014; Sanavi \& Tarighat, 2014; Song, 2016). In addition, instruments that purport to assess students' critical thinking skills include The Watson-Glaser Critical Thinking Appraisal, Cornell Critical Thinking test, and Reflective Thinking Questionnaire (Kember et al., 2000). Nevertheless, these and other instruments have been questioned whether they assess students' critical thinking abilities (Ghanizadeh, 2017). In addition, definitions of critical thinking have been challenged as being Eurocentric - embodying western ideals, ideas, and culture - and culturally biased against Asian students (Song, 2016; Tan, 2017). 


\subsection{Chinese Students}

The number of international students studying in English-dominant countries who do not speak English as their first or primary language continues to rise in the U.S. Students from mainland China are now the largest population of international students studying English, yet they struggle with problem solving, integrating innovative thinking, applying divergent thinking, and combining or synthesizing ideas that may not resemble their past educational experiences (Shapiro, Farrelly, \& Tomas, 2014). The reasons for these difficulties may originate from Chinese classrooms where instruction is predominantly teacher-centered and learning styles are reproductive rather than analytical or speculative (Shi, 2006; Zhang \& Kim, 2018). The 'paradox of the Chinese learner' is based on a set of assumptions: (i) most Chinese students are rote learners with an emphasis on particulars and not universals (i.e. memorizing without understanding); (ii) instruction is repetitious and synonymous with surface learning; and (3) Chinese students should perform poorly academically as a result of classroom instruction (Watkins, 2000, as cited in Shuk Ching Mak, 2013; Sanavi \& Tarighat, 2014). However, data from international assessments suggests that students from China, Hong Kong, Taiwan, and Singapore outperform their Western counterparts (Shuk Ching Mak, 2013; Lu \& Singh, 2017). Further, in contrast with U.S. students who are allowed to choose their areas of study in college after sufficient exploration of their interest, Chinese students enter college with predetermined majors without questioning their own decisions or considering alternative majors to pursue (Zhang, 1999).

\section{Theoretical Framework}

This investigation adopted Perry's theoretical framework to analyze Chinese students' and IEP faculty perceptions of an IEP's C\&CT course as part of their English studies and intellectual development in preparation for college. Perry's theoretical framework has been used by researchers to understand high school and college students' intellectual and ethical development of higher order reasoning (Gainsburg, 2015; Thomas, 2005). The adoption of Perry's theoretical framework in this study relates to the work of other researchers who investigated students' cognitive growth while encountering different cultures in a study-abroad program (Palmer, 2015), developmental differences in gifted high school students (Thomas, 2008), college student's cognitive development to inform career counseling decisions (Mundhenk \& van Zandt, 2005), and mainland Chinese students' intellectual development (Zhang, 1999). Perry's (1970) scheme of intellectual development identified nine stages - positions - held by college students to describe the challenges they experienced in their academic work, social life, and extracurricular activities or places of employment. The nine positions describe the stages of students' intellectual development and transition from a simplistic, dualistic view of the world to a realization of the contingent nature of knowledge and relative values that reflect students' complex levels of thinking and independence of thought and judgment (Knefelkamp, 2003). Students who move from one position to the next reflect an increasingly complex epistemology in which students are generators of their own knowledge, actively processing information and changing the cognitive structure, and becoming aware of their personal and professional identity (Palmer 2015; Buehl \& Alexander, 2001). A student starts from a dualistic view of authority and the world to a final position of personal commitment to career, values, politics, or personal relationships and identity (Thomas 2008). The nine positions are grouped in three categories: dualism, multiplicity of knowledge, and relativism. According to Perry's theory, the first five of nine stages describe many undergraduates in their freshman and sophomore years who score higher on dualism but lower on relativism and commitment in relativism than those in their junior and senior years (Zhang, 1999).

Dualistic thinking (positions 1 and 2) is characterized by a perception of the world and view of knowledge in absolutes, such as right or wrong: "Right answers exists somewhere for every problem and the authorities know them" (Perry, 1970, p. 79). Students resist thinking independently or drawing their own conclusions. Instead, they rely on authorities to provide the "right" answers, believing there is only one and the decision is unexamined with no self-processing (Mundhenk \& van Zandt, 2005). For students, college instructors know and are supposed to impart absolute truth. The movement from one position to the next is assumed the combined result of biological maturity and environmental stimuli that includes instructions and everyday experiences that challenge student's thinking (Gainsburg, 2015).

Students with multiplicity of knowledge (positions 3, 4, and 5) recognize that people hold a diversity of opinions and views, and that any idea is just as good as another. According to Perry (1970), individuals in position 3 see the world from a standpoint in which "uncertainty and complexity are no longer exercises or impediments devised by authority, but seen as realities in their own right ... (T)he student [in position 4] has thus succeeded in preserving a categorical dualism in his world and at the same time has carved out for himself a domain promising absolute freedom" (pp.89, 98). Multiplicity is characterized by the belief in multiple answers and perspectives, where authorities have yet to discover answers to future problems (Shuk Ching Mak, 2013; 
Mundhenk \& van Zandt, 2005).

Students in a position of relativism (positions 6 to 9) recognize that their opinions are based on their values, experiences, and knowledge. In this position of intellectual development, they can make choices and determine the relative merits of alternatives. In this position, students have a clear knowledge of who they are and explore the notion of responsibility. They may identify a career choice as part of their self-identity and seek challenges (Palmer, 2015). Perry (1970) describes a student in position 7 as one who has "undertaken to decide on his own responsibility of who he is, or who he will be, in some major area of his life (for example, "I have decided on medicine")" (pp. 153-154). The next section describes the context of this research and background of the international students who attended the IEP as well as faculty who delivered the curriculum before analyzing the students' and faculty perceptions of the C\&CT course using Perry's theoretical framework.

\section{Methodology}

Each spring and fall semester, an IEP located in a university in the southeast of the United States accepts international students with an intermediate or advanced level of English into a sixteen-week program. Assessment of students' level of English includes a Skype interview of 10 to 15 minutes with an IEP instructor conducted during the student's application process to determine if the international student can understand and communicate in English. Students are placed in an intermediate or advanced class after completing the Michigan English Placement Test, a written essay, and oral interview conducted during the IEP's orientation in the first week of the semester. Between twenty- and twenty-five international students attend full-time English studies in the IEP while living in a university dormitory. More than $90 \%$ of the IEP students are from China ranging in age from 18 to 22 years, with the remaining students from France, Greece, South Korea, Spain, Thailand, Venezuela, or Vietnam. From Monday to Friday, students attend morning classes in listening and speaking, reading and writing, followed by afternoon classes in grammar and structure, college skills, writer's workshop, literary circle, American culture, and an Introduction to Sociology (delivered by a university professor). Students in the IEP also participate in cultural and historical field trips most weekends and meet a university student for at least an hour each week to provide language tutoring and conversation practice. Learner outcomes include writing essays, preparing a research paper, citing sources, understanding an extended lecture, note-taking, delivering presentations, participating in class discussions, and possessing a deeper understanding of American culture and history. Students who successfully complete the intermediate course move to the advanced course, and those who pass the advanced course transition to the host university.

In 2014, IEP students who transferred to the host university received a low or failing grade in first-year History and Political Science courses that required students to demonstrate a degree of originality, critical thinking, or creativity in papers and projects. The IEP instructor and administrator responded to this gap in the students' knowledge and skills with the creation of a two-hour C\&CT course delivered each week. After 4 semesters of delivering the C\&CT course, systematic data collection in this case study began in spring semester 2016 and continued into fall semester 2016 with regular classroom observations collecting field notes of the students' and instructor's words and interactions. Semi-structured interviews were conducted with the IEP assistant director and instructor (Yin, 2009). Born in China, the female IEP administrator lived in the U.S. for more than twenty years, and occupied her role in the IEP for eight years. The female instructor previously taught for five years at an IEP in California before her present role as an instructor in the IEP for five years.

Data collection in 2016 also entailed focus-group interviews with seven female and five male Chinese students who agreed to participate in the study. The Chinese students ranged in age from 19 to 21 years. Three female and two Chinese male students attended the intermediate IEP class, while four female and three male Chinese students were enrolled in the advanced IEP class. During the focus-group interviews, the Chinese students were asked to reflect on the purpose of the C\&CT class, language and learning outcomes, their secondary school experience, and perceived role that the skills of creativity and critical thinking might occupy in a college. Triangulation of data also included analysis of students' written responses after each C\&CT course reflecting on the steps students took to complete a project, aspects they found interesting or challenging, and modifications they would incorporate in a future design or project. In addition, written data was collected from students' anonymous written evaluation of the IEP from a mid-semester student survey and end-of-semester survey that included a question about the $\mathrm{C} \& \mathrm{CT}$ course.

\subsection{C\&CT Course}

The IEP instructor created the C\&CT course with learning outcomes situated in Bloom's level of creation and evaluation. Through online research, consulting books, visiting engineering websites, and surveying students' interests, the instructor identified projects that required the students to plan, produce, modify, evaluate, critique, 
or combine. Categorized under the heading of natural science and social science, each project entailed an element of creativity - developing something new using innovative and collaborative skills - and critical thinking - testing different options to determine the best solution to an open-ended problem. Table 1 identifies some of the natural science and social sciences projects in the C\&CT course that involved the creation of a product demonstrating buoyancy, stability, or propulsion or development of an artefact that communicated persuasion, innovation, or ambition.

Table 1. Categories of C\&CT Projects

\begin{tabular}{|c|c|}
\hline Natural Science & ocial Science \\
\hline $\begin{array}{l}\text { Project: Construct a boat using plastic cups, } \\
\text { drinking straws, plastic wrap, tape, popsicle } \\
\text { sticks. }\end{array}$ & $\begin{array}{l}\text { oject: Create a short movie using technology (iMovie) that } \\
\text { scribes a story from a specific genre, e.g. drama, action, fantasy, } \\
\text { medy, science fiction. }\end{array}$ \\
\hline $\begin{array}{l}\text { Outcome: Buoyancy - Build a boat that will } \\
\text { float and support coins. }\end{array}$ & $\begin{array}{l}\text { Outcome: Artistic imagination - Develop a visual representation } \\
\text { connected to literature. }\end{array}$ \\
\hline & Perry’s Stage: Relativism (positions 6 and 7). \\
\hline $\begin{array}{l}\text { wo tables } \\
\text { lly }\end{array}$ & ond commercial that promotes a \\
\hline $\begin{array}{l}\text { Ict a bridge that } \\
\text { f knowledge }\end{array}$ & $\begin{array}{l}\text { novation - Create an advertisement } \\
\text { roduct or service. } \\
\text { ositions } 6 \text { and } 7 \text { ). }\end{array}$ \\
\hline $\begin{array}{l}\text { Product: Design a car using materials and } \\
\text { rubber bands to propel it forward. } \\
\text { Outcome: Propulsion - Construct a car that } \\
\text { travels the farthest distance. } \\
\text { Perry's Stage: Multiplicity of knowledge } \\
\text { (positions 3, 4, and 5). }\end{array}$ & $\begin{array}{l}\text { Project: Create a visual representation using words and images } \\
\text { taken from magazines that express a student's future career or } \\
\text { aspirations. } \\
\text { Outcome: Goal setting and career reflection - Construct an image } \\
\text { that represents individual goals or opportunities. } \\
\text { Perry's Stage: Relativism (positions 6-7). }\end{array}$ \\
\hline
\end{tabular}

At the start of each C\&CT class, the instructor devoted 10 to 20 minutes describing a problem or project for the students to solve or construct collaboratively. Often the instructor provided project-specific vocabulary to scaffold the learners' understanding of concepts and distributed materials to a complete a project. However, the students did not receive a reading or rubric to structure their thinking about the process or outcome. Instead, the students' active engagement in each class was the intrinsic value of completing the project or competing with other students to win a challenge. Between 60 to 70 minutes of the class involved student discussion and development of a group project with little interruption or guidance from the instructor, except to remind the Chinese students to communicate in English. For the remaining 20 to 30 minutes of the C\&CT class, an individual or group presented a group's finished work or reviewed their classmate's projects. Some projects extended over two weeks but did not repeat from one semester to the next for returning intermediate students moving to the advanced IEP class the following semester.

After each class, students submitted a written or online reflection describing how they developed the product, changes they would consider integrating to their product in the future, interactions with classmates that diminished or contributed positively to the development of the product, and what they learned from the process. Since the inclusion of the C\&CT course in 2014, IEP-alumni in the host university improved their academic performance and maintained a Grade Point Average (G.P.A.) of 3.4/4.0, with more than 50\% selected for the dean's list (G.P.A. of 3.6/4.0) or president's list (G.P.A. of 4.0/4.0).

\section{Findings}

\subsection{Chinese Students' Perceptions}

Interviewed Chinese students claimed that their primary and secondary education in China was teacher-centered with assessments that emphasized recalling information. These educational experiences are consistent with Perry's dualism (position 1) in which teachers occupied a position of authority imparting knowledge that was unexamined by students and assessed with discrete answers to questions:

(Chinese) teachers just give the answer for you: this is the right answer, the other is wrong. You just copy it. 
Only one answer. (Chinese male student)

We do what (the) Chinese teacher tells us what we are told. (Chinese female student)

In China, they (teachers) never ask the students to do independent thinking but remember what the teacher said... (The teachers) expect everybody to get basically the same answer. (Chinese male student)

In focus-group interviews, the Chinese students recalled that a creativity class might have been part of their primary school curriculum, but it was not incorporated in their secondary school studies. In contrast, they speculated that teachers in U.S. secondary schools and colleges emphasized the development of creativity, critical thinking, and analytical skills in students. The Chinese students reasoned that these same skills acquired in American primary and secondary schools would contribute to students' academic success in some college courses and programs. Clustered around Perry's Multiplicity of Knowledge (position 3), the Chinese students reasoned that the American students' secondary school experiences coupled with their knowledge and skills encouraged individual expression and cultivated in American students the values of multiple perspectives and diversity of opinions. The instructor's role in the C\&CT class as well as the student-centered activity encouraged the expression of multiple views and opinions. Some Chinese students contrasted the IEP instructor's role in the C\&CT course with other IEP courses, noting that the IEP instructor accepted multiple answers to a problem or project and avoided explicit direction to guide the students' thinking:

She (the IEP creativity instructor) didn't blame us about what we made. She just accepted it as another way to think differently. (Chinese female student)

I think the way of American teaching is different from China. Critical thinking may be a part of learning in America. (Chinese female student)

American people have too many ideas. It is not too hard for them (to think of ideas). (Chinese male student)

I think every American has (the) ability of creativity...In the U.S., some people think differently from the Chinese. And (if) I think differently, I can know what they (Americans) think. (Chinese female student)

Interviewed Chinese students' claimed the $\mathrm{C} \& \mathrm{CT}$ course developed both their linguistic competencies communicating in English and their higher order cognitive skills of creativity and critical thinking required for future college studies. The Chinese students valued the element of competition in the C\&CT course that they claimed was absent in other IEP courses. Consistent with Perry's multiplicity of knowledge (position 3), students' written reflections of the $\mathrm{C} \& \mathrm{CT}$ course noted the significance of engaging with classmates who had contrasting opinions and different perspectives from themselves. Chinese students valued divergent thinking as an important skill to prepare for college. Chinese students viewed the C\&CT course as a space to not only test ideas and opinions with others who may have conflicting views but develop alternative ways of thinking:

I think it (the C\&CT course) is (a) new way to solve a problem. There are many ways to solve a problem. To be creative is to think of more or new ways to solve a problem that existed before. (Chinese male student)

Everyone has his or her own ideas. If a person cannot accept another idea as not good or practical, he or she has to quit his or her idea. So, this is teamwork: we can learn something about this (compromise), because your idea can't always be the one that works, so you should learn to accept others opinion. (Chinese female student)

When I came up with a wrong idea, my teammates would tell (me) whether my idea was practical or not. Without my teammates, I thought I would have (a) hard time to build the boat only with my idea. In addition, our teammates separated to build different parts of the boat. This accelerated the process of building our boat. They would talk about which idea could be useful and practical to build. Everyone put forward his or her own idea and we discussed it. (Chinese male student)

Chinese students claimed that consensus and compromise was a position adopted after discussing different ideas proposed by IEP students. Reflecting Perry's relativism (position 6), the IEP students recognized that their opinions and their classmates' were based on individual values, experiences, and knowledge. Testing and debating different perspectives before compromising on one strategy involved IEP students determining the relative merits of alternative viewpoints and then arriving at a decision (Perry, 1970):

If everyone has their opinion and is free to discuss, we could finish the tower. Everyone should put forward the point of view, and we put them together to make a perfect plan (to develop the tower). This is the role of teamwork. (Chinese female student)

We spent about one hour in our group to think about how to build the car's body. We came up with at least four different ways but none of them succeeded. In the end, we finished with a rubber-band car, but it couldn't move fast or travel a long distance. (Chinese female student) 
After we finished this game, I learned that engineering was not an easy job. You need (to) have patience and care. (Chinese male student)

I learned a lot from this challenge: knowledge about construction and engineering such as the triangle is the most powerful and stable shape. We used many triangles in our bridge to make it stable. This challenge taught me many things. (Chinese male student)

If an IEP student's product did not demonstrate buoyancy, propulsion, or stability in the natural science project, or did not express individuality or creativity in comparison to others in the social science activity, the individual recognized that the results were a consequence of their developing creative abilities and thinking skills rather than a failure to answer a problem with a correct answer or inability to acknowledge and integrate a diversity of opinions. Students were not constrained in the C\&CT course from the IEP instructor who sought a single, correct answer or knowledge expressed in defined terms. Instead, the C\&CT course provided opportunities and choices for IEP students to acknowledge and reflect upon uncertainty and complexity as well as a range of perspectives that might conflict with their own.

\subsection{Faculty Perceptions}

The course instructor and IEP administrator contrasted the C\&CT course from other IEP courses as a setting that did not integrate assessment requirements while students collaborated to either construct a product or solve a problem. Both individuals described the C\&CT course as a setting to fill a gap in the students' thinking that was perceived to be lacking. With few guidelines and an array of potential solutions, students were asked to think differently in the C\&CT course from other IEP courses that aligned rubrics to learning outcomes. The course instructor and IEP administrator discussed students' intellectual development in the C\&CT course through the lens of Perry's multiplicity of knowledge. That is, they noted the IEP students ruminating on a diversity of opinions and views to arrive at a solution that might be more effective, persuasive, or efficient than an alternative position proposed by another student. The course instructor claimed that students tested ideas in their group and debated viewpoints that elevated the complexity in student's thinking. At times, projects in the C\&CT course resulted in competition between groups in an attempt to produce the strongest or most persuasive product. In this context, reflective of Perry's multiplicity of knowledge, the IEP instructor claimed that her role as an observer without providing students explicit guidance or instructions increased dialogue and debate amongst students and elevated their collaboration through shared opinions and ideas:

The C\&CT course is not the same kind of environment they have in the morning class. The morning classes are very academic: they are all about 'Can you pass the tests?' 'Can you understand what is being said?' There is an answer in the morning class. The morning classes are very structured, with a very specific way of doing things, (such as) taking notes... The C\&CT class is pretty much throwing away the rules. The original concept (of the class) was some kind of activity. They (the students) almost see the C\&CT class as play, but they have to think about a problem and work together to solve it. Usually one person cannot solve the activity (in the C\&CT class): there are multiple solutions to a problem. The students are given a challenge. Some (involve a) challenge they have to solve and others have (an obstacle) to figure out or understand. (The challenge) involves students creating a product. The students' solution comes from their own ideas. There is not a right or wrong way to the challenge. No matter how many times I have done the same activity, the students never produce the same result. I see a bit more bickering (arguing among the students) - not all the time - in the afternoon C\&CT class over what the students want to do. They get competitive with it (the challenge). (IEP Instructor)

The IEP administrator and course instructor said creativity and problem solving abilities were essential for academic success in U.S. colleges but speculated those same abilities might be absent from Chinese students' secondary school education. The course instructor claimed that while Chinese students may not possess the same problem solving skills or innovative thinking abilities that some European or South American students' exhibit, this was not a deficit in Chinese students' thinking. According to the course instructor, Chinese students' demonstrated creativity, critical thinking skills, and problem solving abilities in the C\&CT course as well as produced extended written reflective responses about the projects and activities. Through the lens of Perry's multiplicity of Knowledge (position 3 and 4), the course instructor and IEP administrator viewed the C\&CT course as a space to foster students' thinking about complex problems that prepared them for college. However, the same class challenged students' dualistic thinking (positions 1 and 2) that viewed knowledge in absolutes right or wrong - and put into question the instructor's role as an authority figure who possesses knowledge and truth and provides students with the 'right' answer:

The IEP students can learn how to deal with other people that don't agree or take their ideas. I think that dealing with other people helps them (international students) prepare for university and future group activities... In the 
C\&CT class, IEP students are evaluating their group against another group to find a solution to a problem. In the morning (classes), they think a discussion question has a right answer. They really want me to give them the answer. In the afternoon $\mathrm{C} \& \mathrm{CT}$ class, I think because the challenge is so different, they are not waiting for the teacher's input, because they don't associate it with academic work. There is no pre-reading (in the C\&CT class). The students are not fixed on the correct answer, (so) they are more willing to experiment and play. From this, more individuality comes out from the students. I don't think the C\&CT class is as stressful as the morning classes with the instructor listening to the student's English for accuracy. (IEP Instructor)

In China, we never ask the students to do independent thinking but to remember what the teacher said. (This occurs) not only in China, but other Asian students have the same problem. In China, the thinking follows a straight line: do not go straight or left. Everyone goes this way. The Chinese way of thinking is to follow directions from the teacher and don't think for yourself. Here, in the U.S., individuals think (for himself or herself). (IEP Associate Director)

The IEP administrator suggested that the $\mathrm{C} \& \mathrm{CT}$ course might also occupy the role of introducing IEP students to a college major or future career that they might not have previously considered through the social science and natural science projects. Consistent with Perry's relativism (positions 6 and 7), the IEP administrator viewed the projects in the $\mathrm{C} \& \mathrm{CT}$ course nudging Chinese students' thinking and developing their self-identity to explore a future college major or career path in a different direction from the one that might have been influenced from their parent's or guardian's recommendation:

Usually Chinese parents make a decision (for their son or daughter) of what major to study, either the sciences or social studies.... Chinese students have never had the opportunity to explore or to discover what they really want to study. If they have a class that gives them the opportunity to discover their interest to choose the major they are interested in, they can ask themselves: Do I really want to study this? The C\&T class might change their thinking. In the C\&CT class, one-week is a science-related focus (projects), and another week is a social science focus. I hope the students can become an inventor and create something no one has thought of, or become an engineer, or writer, or thinker, or professor... If the IEP students start to think out-of-the-box - to make connections - when they go to college, they will do better. (IEP Associate Director)

\section{Discussion}

This study investigated the reasons why an IEP integrated a C\&CT course into its program and perceptions of the same course by IEP faculty and Chinese students. This study provided insights into the strategies an IEP instructor utilized in the C\&CT course to promote students' abilities to think creatively and complexly. IEP faculty explained the inclusion of the C\&CT course to address a perceived gap in some international students' creativity and critical thinking skills. Recognized as a primary goal and learning outcome in college (Feng, 2013), the IEP faculty viewed the C\&CT course as a space in the IEP curriculum to foster higher order thinking skills and competencies for international students' academic preparation for college. Perry's (1970) nine stages of intellectual development provided a theoretical framework to systematically analyze Chinese students' and IEP faculty perceptions of the $\mathrm{C} \& \mathrm{CT}$ course according to dualistic thinking, multiplicity of knowledge, and relativism.

In answer to the first research question, What are the learning outcomes of a creativity and critical thinking course in an IEP?, this study found international students collaborating in the C\&CT course that fostered divergent thinking and consensus. The IEP instructor's diminished role of authority and facilitator of knowledge elevated the students' communication and collaboration skills that required students to utilize their creativity and critical thinking abilities. Chinese students observed a distinction between the instruction and learning outcomes experienced in the C\&CT course and other IEP courses where the instructor's facilitated student's learning and the learning outcomes were defined. IEP faculty claimed the projects and problems in the C\&CT course would cultivate in Chinese students a diversity of opinions and views that are reflective of a complex and uncertain world.

In response to the second research question, What are Chinese students' and IEP faculty perceptions of a creativity and critical thinking course?, interviewed Chinese students and the IEP administrator reflected on the paucity of creative or critical thinking skills in Chinese students' secondary school experience that focused on memorization. Reflecting Perry's multiplicity of knowledge, Chinese students expressed a need to develop the same cultural and strategic competences of creativity, problem solving, and critical thinking skills exhibited by American students that Chinese student also perceived to be valued in college. While Chinese students in this research noted that their secondary school education emphasized memorization at the expense of higher order thinking skills, faculty interviews and classroom observations revealed those Chinese students' debated and 
tested ideas with others in small groups to produce, through consensus, a collaborative product. Through written reflections, Chinese students also expressed individual views and provided alternative strategies to solve a problem or create a product in the $\mathrm{C} \& \mathrm{CT}$ course.

The C\&CT course described in this study created opportunities for English learners to cultivate their higher order thinking abilities through encounters with ill-structured problems that is an implicit part of creativity and risk-taking (Pappano, 2014; Thomas, 2008). In the C\&CT course, language learners had the opportunity to make choices that affected their cognitive development and integration of new knowledge (Zhang, 1999). In addition, IEP students in the C\&CT course collaborated to develop, without reference to an authority figure or model to arrive at a solution, intellectual competencies such as compromise and recognition of diverse opinions and views.

This study supports other research that shifts the rhetoric from Chinese students who experienced an education that emphasized rote and passive learning and do not publicly express their views in class to a discourse of difference that recognizes Chinese students' perspectives, accounts for their background characteristics, personal histories, abilities, attitudes, and behavior (Evens, Verburgh, \& Elen, 2013; Lu \& Singh, 2017; Tan, 2017). While Chinese students' and first-generation Asian American students' language and dispositions display a deference to authority that may be interpreted as dualistic in Perry's theoretical framework (Thomas, 2008), they often display a complexity of thought and critical views sometimes expressed through less threatening and more culturally appropriate formats, such as essay writing and small-group discussions (Tan, 2017). Understanding the intellectual development among Chinese students may be a challenge because of cultural expectations and behavior that may not reflect their thinking (Knefelkamp, 2003; Thomas, 2008).

Students who study English as an additional language need a high-level of language proficiency to become independent language users who can manage content-based tasks and achieve culture-merging views on diverse problems (Wang \& Zheng, 2016; Wang, Lai, \& Leslie, 2015). Indeed, students' beliefs about knowledge play a powerful role in their academic performance and knowledge acquisition (Buehl \& Alexander, 2001). IEP administrators and course instructors confront the challenge of how to prepare international students for U.S. colleges in which two of many goals of an undergraduate education is to promote creativity and foster higher order reasoning in students (Shapiro, Farrel, \& Tomas, 2014; Shim \& Walczak, 2016; Shuk Chung Mak, 2013). However, teaching critical thinking and creativity remains a challenge for IEP teachers. For teachers who take forward changes to a program or curriculum, they need the support of administrators (Zhang \& Kim, 2018). In this regard, incorporating theories and strategies in teacher training, professional development workshops, and curriculum can help IEP instructors and administrators to meet the challenge of cultivating English language learners' higher order thinking abilities and creativity skills (Feng, 2013; Tous, Tahriri, \& Haghighi, 2015).

The C\&CT course provided English learners with the opportunity to prepare for future academic, professional, and global challenges while also introducing IEP students to potential majors to pursue in college (Gainsburg, 2015). However, IEP administrators and instructors continue to search for ways to foster English learners' creative thinking and analytical skills. This study is constrained by some limitations. The small sample size prevents this research from generalizing results to other IEPs. In addition, the study did not interview non-Chinese students to determine their perceptions of the C\&CT course. Future research is recommended to investigate whether IEP students are able to operationalize their creative thinking and analytical skills across an IEP curriculum from a stand-alone C\&CT course (Flores, Matkin, Burbach, Quinn, \& Harding, 2012). Future research might also study how IEP's foster higher order reasoning in English learners from diverse cultures and linguistic backgrounds.

\section{References}

AACU (American Association of Colleges and Universities) (2016). College Learning for the New Global Century. Retrieved from https://secure.aacu.org/AACU/PDF/GlobalCentury_ExecSum_3.pdf

Buehl, M. M., \& Alexander, P. A. (2001). Beliefs about academic knowledge. Educational Psychological Review, 13(4), 385-418. https://doi.org/10.1023/A:1011917914756

Cross, R. (2012). Creative in finding creativity in the curriculum: the CLIL second language classroom. Australian Educational Researcher, 39(4), 431-445. https://doi.org/10.1007/s13384-012-0074-8

Evens, M., Verburgh, A., \& Elen, J. (2013) Critical thinking in college freshmen: The impact of secondary and higher education. International Journal of Higher Education, 2(3), 139-151.

https://doi.org/10.5430/ijhe.v2n3p139

Feng, Z. (2013). Using teacher questions to enhance EFL students' critical thinking ability. Journal of 
Curriculum and Teaching, 2(2), 147-153. https://doi.org/10.5430/jct.v2n2p147

Flores, K. L., Matkin, G. S., Burbach, M. E., Quinn, C. E., \& Harding, H. (2012). Deficient critical thinking skills among college graduates: Implications for leadership. Educational Philosophy and Theory, 44(2), 212-230. https://doi.org/10.1111/j.1469-5812.2010.00672.x

Gainsburg, J. (2015). Engineering students' epistemological views on mathematical methods in engineering. The Journal of Engineering Education, 104(2), 139-166. https://doi.org/10.1002/jee.20073

Getahun, D. A., Saroyan, A., \& Aulls, M. W. (2016). Examining undergraduate students' conceptions of inquiry in terms of epistemic belief differences. Canadian Journal of Higher Education, 46(2), 181-205.

Ghanizadeh, A. (2017). The interplay between reflective thinking, critical thinking, self-monitoring, and academic achievement in higher education. Higher Education, 74(1), 101-114.

https://doi.org/10.1007/s10734-016-0031-y

Gibson, R. (2010). The 'art' of creative teaching: implications for higher education. Teaching in Higher Education, 15(5), 607-613. https://doi.org/10.1080/13562517.2010.493349

Grant, M., \& Smith, M. (2018). Quantifying assessment of undergraduate critical thinking. Journal of College Teaching \& Learning, 15(1), 27-38. https://doi.org/10.19030/tlc.v15i1.10199

Harris, A., \& de Bruin, L. R. (2018). Secondary school creativity, teacher practice and STEAM education: An international study. Journal of Educational Change, 19(2), 153-179. https://doi.org/10.1007/s10833-017-9311-2

Jahnke, I., Haertel, T., \& Wildt, J. (2017). Teachers' conceptions of student creativity in higher education. Innovations in Education and Teaching International, 54(1), 87-95. http://dx.doi.org/10.1080/14703297.2015.1088396

Kember, D., Leung, D. Y. P., Jones, A., Yuen Loke, A., McKay, J., Sinclair, K., \& Yeung, E. (2000). Development of a questionnaire to measure the level of reflective thinking. Assessment \& Evaluation in Higher Education, 25(4), 380-395. https://doi.org/10.1080/713611442

Knefelkamp, L. L. (2003). The influence of a classic. Liberal Education, 89(3), 10-15.

Lennon, N. K. (2014). How Professors Infuse Critical Thinking into College Courses. Seton Hall University Dissertations and Theses (ETDs). Retrieved from http://scholarship.shu.edu/dissertations/2004.

Lu, S., \& Singh, M. (2017). Debating the capabilities of "Chinese students" for thinking critically in Anglophone universities. Education Sciences, 7(22), 1-16. https://doi.org/10.3390/educsci7010022

Lucas, B. (2016). A five-dimensional model of creativity and its assessment in schools. Applied Measurement in Education, 29(4), 278-290. http://dx.doi.org/10.1080/08957347.2016.1209206

Marquis, E., \& Henderson, J. A. (2015). Teaching creativity across disciplines at Ontario universities. Canadian Journal of Higher Education, 45(1), 148-166.

Moore, T. (2013). Critical thinking: Seven definitions in search of a concept. Studies in Higher Education, 38(4), 506-522. https://doi.org/10.1080/03075079.2011.586995

Mundhenk, L. G., \& van Zandt, Z. (2005). Using cognitive development theory in higher education career development program. Career Planning and Adult Development Journal, 21(1), 81-91.

Palmer, N. W. (2015). Inverting the object of study: Recalibrating the frame of reference in study abroad experiences. Teaching Theology and Religion, 18(1), 63-72. https://doi.org/10.1111/teth.12264

Pappano. L. (2014). Learning to think outside the box. New York Times. Retrieved from https://www.nytimes.com/2014/02/09/education/edlife/creativity-becomes-an-academic-discipline.html

Paul, R. W. (1993). The logic of creative and critical thinking. American Behavioral Scientist, 37(1), 21-39. https://doi.org/10.1177/0002764293037001004

Pei, Z., Zheng, C., Zhang, M., \& Liu, F. (2017). Critical thinking and argumentative writing: Inspecting the association among EFL learners in China. English Language Teaching, 10(10), 31-42. https://doi.org/10.5539/elt.v10n10p31

Perry, W. G. (1970). Forms of intellectual and Ethical Development in the College Years. New York: Harcourt, Brace, Jovanovich, Inc.

Sanavi, R. V., \& Tarighat, S. (2014). Critical thinking and speaking proficiency: A mixed-method study. Theory 
and Practice in Language Studies, 4(1), 79-87. https://doi.org/10.4304/tpls.4.1.79-87

Shapiro, S., Farrelly, R., \& Tomas, Z. (2014). Fostering International Student Success in Higher Education. Alexandria, Virginia: TESOL press.

Shi, L. (2006). The successors to Confucianism or a new generation? A questionnaire study on Chinese students' culture of learning English. Language, Culture and Curriculum, 19(1), 122-147. https://doi.org/10.1080/07908310608668758

Shim, W-J., \& Walczak, K. (2012). The impact of faculty teaching practices on the development of students' critical thinking skills. International Journal of Teaching and Learning in Higher Education, 24(1), 16-30.

Shuk, C. M. J. (2013). How do students from China studying at U.S. Engineering graduate degree programs develop along the Perry Scheme. Dissertation, Teachers College, Columbia University.

Song, X. (2016). 'Critical thinking' and pedagogical implications for higher education. East Asia, 33, 25-40. https://doi.org/10.1007/s12140-015-9250-6

Steadman, A., \& Kraut, R. (2018). Preparing the online language program administrator: A needs analysis of intensive English programs in the United States. CALICO Journal, 35(3), 274-294. https://doi.org/10.1558/cj.34636

Tan, C. (2017). Teaching critical thinking: Cultural challenges and strategies in Singapore. British Educational Research Journal, 43(5), 988-1002. https://doi.org/10.1002/berj.3295

Thomas, J. A. (2008). Reviving Perry: An analysis of epistemological change by gender and ethnicity among gifted high school students. Gifted Child Quarterly, 52(1), 87-98. http://dx.doi.org/10.1177/0016986207311422

Tous, M. D., Tahriri, A., \& Haghighi, S. (2015). The effect of instructing critical thinking through debate on male and female EFL learners' reading comprehension. Journal of the Scholarship of Teaching and Learning, 4(15), 21-40. https://doi.org/10.14434/josotl.v15i4.13191

Wang, D, Lai, H., \& Leslie, M. (2015). Chinese English learners' strategic competence. Journal of Psycholinguist Research, 44(6), 701-714. http://dx.doi.org/10.1007/s10936-014-9313-7

Wang, X., \& Zheng, H. (2016). Reasoning critical thinking: Is it born or made? Theory and Practice in Language Studies, 6(6), 1323-1331. https://doi.org/10.17507/tpls.0606.25

Welter, M. M., Jaarsveld, S., \& Lachmann, T. (2017). Problem space batters: The development of creativity and intelligence in primary School Children. Creativity Research Journal, 29(2), 125-132. https://doi.org/10.1080/10400419.2017.1302769

Yin, R. K. (2009). Case Study Research, Fourth Edition. Thousand Oaks, California: Sage.

Zhang, L F. (1999). A comparison of U.S. and Chinese university students' cognitive development: The cross-cultural applicability of Perry's theory. The Journal of Psychology, 133(4), 425-439. https://doi.org/10.1080/00223989909599753

Zhang, L., \& Kim, S. (2018). Critical thinking cultivation in Chinese college English classes. English Language Teaching, 11(8), 159-164. https://doi.org/10.5539/elt.v11n8p159

\section{Copyrights}

Copyright for this article is retained by the author(s), with first publication rights granted to the journal.

This is an open-access article distributed under the terms and conditions of the Creative Commons Attribution license (http://creativecommons.org/licenses/by/4.0/). 